\title{
Elytra colour polymorphism and randomness of matings in Chauliognathus fallax Germar 1824 from southern Brazil (Coleoptera, Cantharidae)
}

Vilmar Machado ${ }^{1}$

Aldo Mellender de Araújoº

\begin{abstract}
Beetles of the species Chauliognathus fallax Germar 1824 are polymorphic for elytron colouration with six morphs distinguished on the basis of black pigmentation on a yellow background. We investigated samples of $C$. fallax taken in eight consecutive weeks aiming to determine the frequency of the morphs which were grouped, for statistical analysis, into three classes according to elytra pigmentation as well as the possible occurrence of assortative mating. Our results showed a variation in the frequency of the classes throughout the season, both in males and females, with the maximum frequency of each class at the fourth and fifth week. The three classes (A, B, C) showed the same pattern of variation, and class B was always the more frequent. To test randomness of matings two approaches were taken: in the first, we compared the frequency of each class in copulating and non-copulating insects. In the second, the frequency of each class in the whole sample was taken as the probability of occurrence of the respective class; then, using the criterion of the probability of independent events we calculated the expected proportion of copulating insects for each pair of events. Both methods gave non-significant differences, suggesting that the matings were random.
\end{abstract}

Keywords. Assortative mating; Chauliognathus; Coleoptera; colour polymorphism.

\section{INTRODUCTION}

The maintenance of genetic polymorphism is considered one of the central problems in population genetics. However, the emphasis in the last decades on molecular polymorphisms has displaced studies on colour polymorphism (HOFFMANN $e t$ al. 1995). On the other hand, animal colours have been strongly discussed under the heading of evolutionary ecology, exemplifying mainly the communication between prey and predator as well as that between the sexes (ENDLER 1978, 1993 $a, b)$.

Beetles of the genus Chauliognathus Hentz, 1930 (Coleoptera, Cantharidae) show several features that make them highly suitable for studies both in population genetics and evolutionary ecology. Some species are polymorphic for colour pattern of elytra and/or pronotum, such as $C$. flavipes Fabricius, 1781 from the State of Rio Grande do Sul, Brazil, where the extensive geographical variation contrasts with the temporal stability of the polymorphism (MACHADO \& ARAÚJO
1995). Also for the North American species C. basalis Lacordaire, 1837, it has been reported a high degree of polymorphism for pronotum colouration in populations from Colorado, USA (BERNSTEIN \& BERNSTEIN 1996).

The phenomenon of assortative mating has already been described in species of that genus. McCAulEY \& WADE (1978) and McLain (1982), showed the occurrence of preferential mating related to size in the species $C$. pennsylvanicus De Geer, 1774, which is however a monomorphic species for colour. BeRNSTEIN \& BernsteIn (1998) also ascertained size-related assortative mating in $C$. basalis and $C$. deceptus Fender, 1964. Southern Brazilian populations of the polymorphic species $C$. flavipes have been studied by Diehl-Fleig \& Araúso (1991) and by Machado \& AraúJo (1999), using elytra colour pattern as the variable involved in the preference with contradictory results. The first authors found positive assortative mating, while this was not found by Machado \& ARAúJo, which explain the possible causes for the different results.

\footnotetext{
1. Laboratório de Genética, Universidade do Vale do Rio dos Sinos, UNISINOS. Caixa Postal: 275, 93022-000 São Leopoldo-RS, Brazil. E-mail: machado@bios.unisinos.br

2. Departamento de Genética, Universidade Federal do Rio Grande do Sul. Caixa Postal 15053, 91501-970 Porto Alegre-RS, Brazil.

E-mail: aldomel@portoweb.com.br
} 
Table I. Number and percentage for each morph and sex of Chauliognathus fallax at every week of sampling. A - males; B - females.

\begin{tabular}{|c|c|c|c|c|c|c|c|c|c|c|c|c|c|}
\hline Week/morphs & 1 & $\%$ & 2 & $\%$ & 3 & $\%$ & 4 & $\%$ & 5 & $\%$ & 6 & $\%$ & Total \\
\hline \multicolumn{14}{|l|}{$\mathbf{A}$} \\
\hline 07/XI/1996 & 7 & 5 & 2 & 40 & 17 & 2 & 3 & 2 & 3 & 1 & 0 & 0 & 32 \\
\hline 14/XI/1996 & 15 & 11 & 1 & 20 & 124 & 11 & 22 & 14 & 30 & 10 & 2 & 50 & 194 \\
\hline 21/XI/1996 & 8 & 5 & 0 & 0 & 186 & 17 & 15 & 9 & 45 & 15 & 0 & 0 & 254 \\
\hline 28/XI/1996 & 35 & 25 & 1 & 20 & 240 & 22 & 37 & 23 & 77 & 26 & 0 & 0 & 390 \\
\hline 05/XII/1996 & 33 & 23 & 1 & 20 & 177 & 16 & 38 & 24 & 54 & 18 & 2 & 50 & 305 \\
\hline 12/XII/1996 & 12 & 8 & 0 & 0 & 138 & 13 & 17 & 11 & 45 & 15 & 0 & 0 & 212 \\
\hline 19/XII/1996 & 18 & 13 & 0 & 0 & 126 & 12 & 18 & 11 & 34 & 11 & 0 & 0 & 196 \\
\hline 26/XII/1996 & 14 & 10 & 0 & 0 & 78 & 7 & 10 & 6 & 13 & 4 & 0 & 0 & 115 \\
\hline Total & 142 & & 5 & & 1086 & & 160 & & 301 & & 4 & & 1698 \\
\hline \multicolumn{14}{|l|}{ B } \\
\hline 07/XI/1996 & 0 & 0 & 2 & 18 & 30 & 3 & 10 & 2 & 2 & 25 & 0 & 0 & 44 \\
\hline 14/XI/1996 & 9 & 15 & 4 & 36 & 142 & 13 & 65 & 16 & 1 & 12 & 0 & 0 & 221 \\
\hline 21/XI/1996 & 5 & 8 & 0 & 0 & 164 & 15 & 53 & 13 & 0 & 0 & 0 & 0 & 222 \\
\hline 28/XI/1996 & 8 & 14 & 2 & 18 & 284 & 26 & 99 & 25 & 1 & 12 & 0 & 0 & 394 \\
\hline 05/XII/1996 & 20 & 34 & 0 & 0 & 210 & 19 & 86 & 22 & 0 & 0 & 0 & 0 & 316 \\
\hline 12/XII/1996 & 3 & 5 & 0 & 0 & 115 & 10 & 36 & 9 & 1 & 12 & 0 & 0 & 155 \\
\hline 19/XII/1996 & 8 & 14 & 2 & 18 & 85 & 8 & 26 & 6 & 0 & 0 & 0 & 0 & 121 \\
\hline 26/XII/1996 & 6 & 10 & 1 & 9 & 67 & 6 & 28 & 7 & 3 & 39 & 0 & 0 & 105 \\
\hline Total & 59 & & 11 & & 1097 & & 403 & & 8 & & 0 & & 1578 \\
\hline
\end{tabular}

Here we studied the frequency of different colour morphs in Chauliognathus fallax Germar, 1824 throughout the season and analysed whether there is random or assortative mating in order to find out one of the possible causes in the maintenance of the elytra polymorphism.

\section{MATERIALAND METHODS}

Study sites. Beetles were collected at Fazenda Santa Isabel, municipality of Guaíba, RS, Brazil. Two natural fields ( 0.5 ha each) were examined for the presence of the beetles between October $17^{\text {th }}, 1996$ and January $2^{\text {nd }}, 1997$; they appeared only on November $7^{\text {th }}$, being absent from December $26^{\text {th }}$ on, which

\begin{tabular}{lllll}
\hline Classes $/ \mathrm{A}$ & $\mathrm{B}$ & $\mathrm{C}$ & $\mathrm{D}$ \\
\hline
\end{tabular}
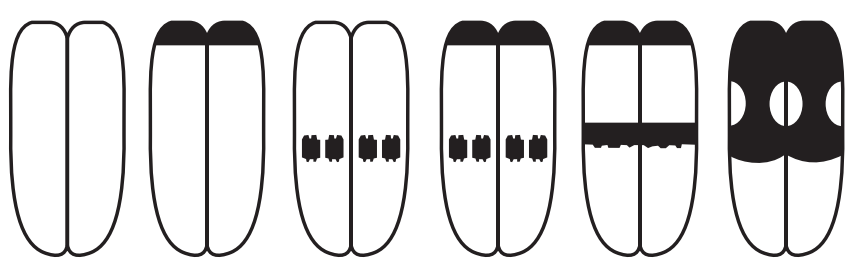

$\begin{array}{llllll}1 & 2 & 3 & 4 & 5 & 6 \\ \text { Morphs } & & & & \end{array}$

Fig. 1. Elytra of the six morphs found in Chauliognathus fallax grouped into four classes. Class D was excluded of the analysis due to the small number of individuals (only 4). represents the first and the last of the eight weeks referred latter. The fields were about $100 \mathrm{~m}$ apart from each other and were separated by a small wood. The vegetation consisted predominantly of grasses and Eryngium sp. (Tourn.) L. (Apiaceae). Beetles on flowers were sampled one day per week (between $10 \mathrm{~h}$ and $12 \mathrm{~h}$ ); the insects were captured by hand, scored for the type of morph and then stored in glasses to be later released (pairs in copulation were stored in individual glasses). Although always feeding on pollen they changed hosts, first using Myrceugenia campestris (DC.) Legr. et Kaus. (Myrtaceae) and Struthantus polyrhizus Mart. (Loranthaceae) in the first week and then Eryngium sp. until the last week. For statistical analyses, we used contingency or heterogeneity chi-square (Sokal \& Rohlf 1995). A sample comprising all the phenotypes found were deposited in the Cantharidae collection of the Laboratório de Genética from UNISINOS.

Colour polymorphism and matings. Colour patterns of $C$. fallax were classified basically by the presence of black spots or stripes on the elytra; six morphs were recognized and numbered 1 through 6 (Table I; Fig. 1). For the analysis we joined morphs according to the increased degree of melanization of elytra. In accordance with this criterion, morphs 1 and 2 form class A; class B consisted only of morph 3 , and morphs 4 and 5 formed class C. Morph 6 (the more pigmented) appeared in only four individuals, and so was excluded from the analysis. To analyse the randomness of matings, the morphs of both partners of copulating pairs were recorded and compared with non-copulating individuals. Moreover, the overall frequency of each class (A, B, C) was used as the probability of finding 
Table II. Test of independence between the number of $C$. fallax for each phenotypic class and week (morphs 1,2, class A; morph 3, class B; morphs 4, 5, class C; morph 6 discarded due to small number of individuals - see Table I). Heterogeneity $\chi^{2}$ between the sexes not significant.

\begin{tabular}{|c|c|c|c|c|c|c|}
\hline Males & $\mathbf{A}$ & B & C & $x^{2}$ & d.f. & $P$ \\
\hline 07/XI/1996 & 9 & 17 & 6 & 32.428 & 14 & $<0.01$ \\
\hline 14/XI/1996 & 16 & 124 & 52 & & & \\
\hline 21/XI/1996 & 8 & 186 & 60 & & & \\
\hline 28/XI/1996 & 36 & 240 & 114 & & & \\
\hline 05/XII/1996 & 34 & 177 & 92 & & & \\
\hline 12/XII/1996 & 12 & 138 & 62 & & & \\
\hline 19/XII/1996 & 18 & 126 & 52 & & & \\
\hline 26/XII/1996 & 14 & 78 & 23 & & & \\
\hline Total & 147 & 1086 & 461 & & & \\
\hline
\end{tabular}

\begin{tabular}{|c|c|c|c|c|c|c|}
\hline Females & $\mathbf{A}$ & B & C & $\chi^{2}$ & d.f. & $P$ \\
\hline $07 / \mathrm{XI} / 1996$ & 2 & 30 & 12 & 23.46 & 14 & N.S. \\
\hline 14/XI/1996 & 13 & 142 & 66 & & & \\
\hline 21/XI/1996 & 5 & 164 & 53 & & & \\
\hline 28/XI/1996 & 10 & 284 & 100 & & & \\
\hline 05/XII/1996 & 20 & 210 & 86 & & & \\
\hline 12/XII/1996 & 3 & 115 & 37 & & & \\
\hline 19/XII/1996 & 10 & 85 & 26 & & & \\
\hline 26/XII/1996 & 7 & 67 & 31 & & & \\
\hline \multirow[t]{4}{*}{ Total } & 70 & 1097 & 411 & & & \\
\hline & & & Total $\chi^{2}$ & 55.89 & 28 & $<0.01$ \\
\hline & & & Pooled $\chi^{2}$ & 42.86 & 14 & $<0.01$ \\
\hline & & & Heterog. $\chi^{2}$ & 13.03 & 14 & N.S \\
\hline
\end{tabular}

such class to estimate the expected frequency of each mating.

\section{RESULTS}

Colour polymorphism. The data were analysed in two complementary ways: first taking into account each sample (week) separately to estimate the frequency of the classes for each sex (per week); this is showed in Table II, for absolute numbers. These numbers were used as entries in a contingency table $(8 \times 3)$ to test for an association between week and class. Males showed highly significant differences in the frequency of classes A, B, and C per week $\left(\chi^{2}=32.43 ; 14\right.$ d.f.; $\mathrm{P}<0.01)$. Females, on the other hand, are close to statistical significance $\left(\chi^{2}=23.46 ; 14\right.$ d.f.; $\left.0.05<\mathrm{P}<0.10\right)$. Both sexes, however, showed the same pattern, as suggested by the non-significant heterogeneity chi-square $\left(\chi^{2}=13.03 ; 14\right.$ d.f.; $\mathrm{P}$ $>0.50$ ). Due to this reason they are pooled in Fig. 2; the range of variation for each class was, respectively for class A, B, and C, $62-74 \%, 24-29 \%$ and 3-14\%.

For descriptive purposes, we also considered the number of beetles in each class and week in relation to the total number caught in the respective class; these frequencies can be considered an estimate of the recruitment rate per class (Table III, Fig. 3). There is a peak of recruitment at the fourth/fifth week of sampling.

Randomness of matings. To test for randomness of matings two approaches were taken: in the first we tested for an association between the frequency of the respective class in copulating and non-copulating beetles (Table IV); no association was detected. A second test consisted in comparing the expected frequency of each pair in copulation with the observed one (see Materials and Methods for details); again, a non-significant result was obtained (Table V). In order to eliminate the effects of a biased sex ratio for each class of morphs, chi-square statistics were applied each week to test for sex ratio proportions. Only in the sixth and seventh week of sampling there was a significant departure from the expected 1 male $: 1$ female $\left(\chi^{2}=8.85 ; 1\right.$ d.f.; $\left.P<0,01\right)$.

\section{DISCUSSION}

Soldier beetles had been used to study the process and consequences of assortative mating. The variables employed in these studies are the spot length (Chauliognathus pennsylvanicus see MASON 1972), spot width, dry weight and antennal scape diameter (C. pennsylvanicus see McLaIN 1982, 1985), polymorphism of elytra colour in C. fallax and C. flavipes (Diehl-Fleig \& Araújo 1991; Machado \& Araújo 1995, 1999), and elytra length $(C$. basalis and $C$. deceptus) (BERNSTEIN \& BERNSTEIN 1998). Whichever the variables used to evaluate the occurrence of assortative mating, the findings of positive assortative mating reported in the above papers are inconsistent. It seems that the detection of non-random 
Table III. Number of individuals for each phenotypic class (A, B, C) every week. M= males; F=females. Percentages were estimated for each week considering males plus females $(\mathrm{T})$, in relation to the total number of beetles during the eight weeks (here defined as recruitment).

\begin{tabular}{crrrrrrrrrrrr}
\hline Week/morphs & \multicolumn{3}{c}{ A } & \multicolumn{1}{c}{ B } & \multicolumn{3}{c}{ C } \\
\hline & M & F & T & $\%$ & M & F & T & $\%$ & M & F & T & $\%$ \\
\hline 1 & 9 & 2 & 11 & 5 & 17 & 30 & 47 & 2 & 6 & 12 & 18 & 2 \\
2 & 16 & 13 & 29 & 13 & 124 & 142 & 266 & 12 & 52 & 66 & 120 & 14 \\
3 & 8 & 5 & 13 & 6 & 186 & 164 & 350 & 16 & 60 & 53 & 113 & 13 \\
4 & 36 & 10 & 46 & 21 & 240 & 284 & 524 & 24 & 114 & 100 & 214 & 24 \\
5 & 34 & 20 & 54 & 25 & 177 & 210 & 387 & 18 & 92 & 86 & 180 & 21 \\
6 & 12 & 3 & 15 & 7 & 138 & 115 & 253 & 12 & 62 & 37 & 99 & 11 \\
7 & 18 & 10 & 28 & 13 & 126 & 85 & 211 & 10 & 52 & 26 & 78 & 9 \\
8 & 14 & 7 & 21 & 10 & 78 & 67 & 145 & 7 & 23 & 31 & 54 & 6 \\
\hline Total & 147 & 70 & 217 & & 1086 & 1097 & 2183 & & 461 & 411 & 876 \\
\hline
\end{tabular}

Table IV. Test of the association between the number of males (a) and females (b) for each phenotypic class and copulating / non-copulating individuals of $C$. fallax.

\begin{tabular}{lllllccc}
\hline & Class & A & B & C & $\boldsymbol{\chi}^{2}$ & d.f. & $\boldsymbol{P}$ \\
\hline (a) & Copulating & 49 & 419 & 167 & & & N. S. \\
& Non-copulating & 57 & 446 & 217 & 2.635 & 2 & N.S. \\
& & & & & & 2 & \\
(b) & Copulating & 29 & 451 & 155 & & & \\
& Non-copulating & 22 & 464 & 187 & 3.040 & & \\
\hline
\end{tabular}

Table V. Test of randomness of matings by comparing observed and expected number of copulating $C$. fallax according to the phenotypic class.

\begin{tabular}{lccccccccc}
\hline & A x A & $\mathbf{A ~ x ~ B ~}$ & A x C & B x B & B x C & C x C & $\boldsymbol{\chi}^{2}$ & d.f. & $\boldsymbol{P}$ \\
\hline Observed & 4.0 & 57.0 & 13.0 & 303.0 & 209.0 & 49.0 & 7.787 & 5 & N. S. \\
Expected & 2.3 & 5.1 & 20.6 & 286.1 & 229.7 & 46.3 & & & \\
\hline
\end{tabular}

mating in some populations but not in others, is related to other variables, as, for instance, the density of individuals or the presence/absence of a sympatric species.

This report deals with a single population, which could be a disadvantage as compared to other studies; however the fact that the population was followed during eight consecutive weeks is relevant (this procedure was already used in our previous papers, MACHADO \& ARAÚJO 1998, 1999). In those species studied so far in the State of Rio Grande do Sul,
Southern Brazil, recruitment rates of the phenotypic classes are different between the sexes, implying that at a given time the frequency of a copulating pair (as far as colour is concerned) could be over/underestimated. So, the occurrence of nonrandom mating could be only an artifact. We think even that this could explain some of the inconsistencies reported in the literature. It is relevant to this matter the following remark by BERNSTEIN \& BERNSTEIN (1998): “Temporal covariation may cause positive assortative mating if the sizes of males and

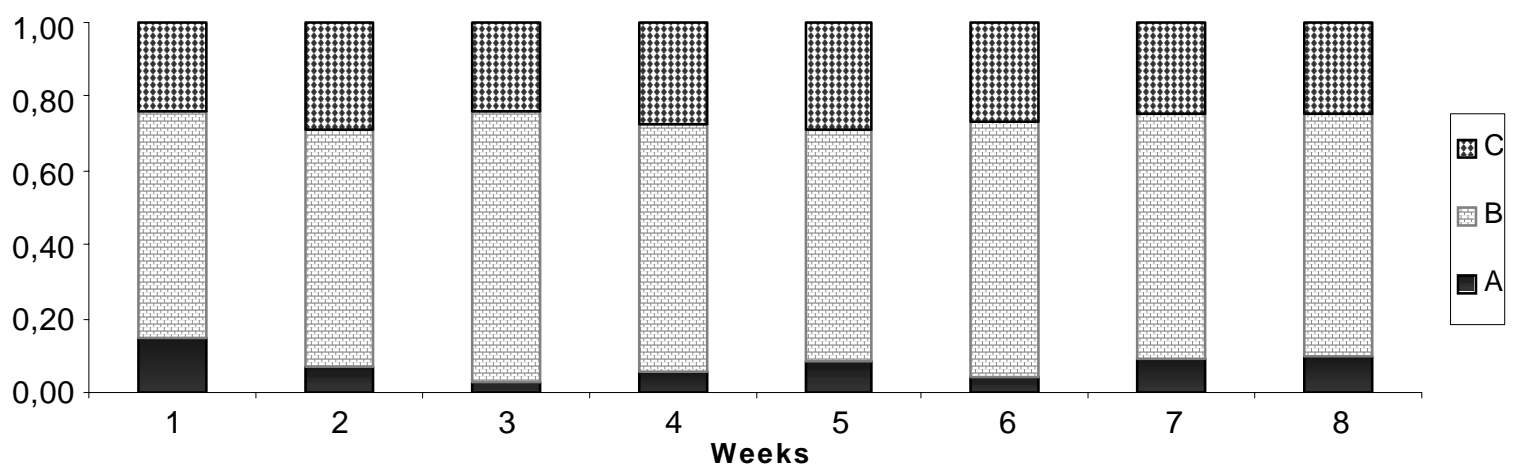

Fig. 2. Relative frequencies of individuals (\%) of each colour class of Chauliognathus fallax, per sample. 


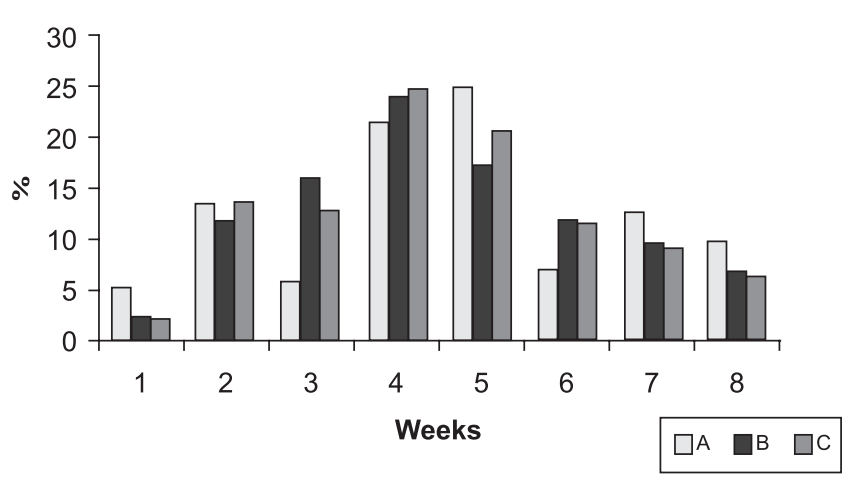

Fig. 3. Variation in the recruitment (\%, see Table III) of each colour class of Chauliognathus fallax during the period of study.

females vary in a similar way over time, and pairs remain coupled for periods of time that are relatively long compared to emergence time (or if samples taken at different times are pooled). Thus we reasoned that if the beetles that breed earlier are larger or smaller than the beetles that breed later, then a sample taken midway through the season may include pairs that have been mated for a relatively long time (the early breeders, of a similar size) as well as pairs that have just begun to mate (the late breeders, of a similar size but larger or smaller than the beetles that began mating earlier). This particular sample would show positive assortative mating whereas a sample taken earlier or later in the season may not" (p. 63). They discussed for size what we are discussing for colour pattern.

In the present paper we approached the question of randomness of matings in two ways. Both analyses showed no evidence of preferential mating (Tables IV and V). Moreover, as what might be seen as a third way to analyse the data (not showed here), each week was independently analysed; applying the same procedure as before, again no significant results were obtained. It seems then that $C$. fallax mates at random as far as colour of the morphs is concerned, as does C. flavipes (MACHAdo \& ARAúJo 1999).

The results reported here, as well as others from the literature, seem to indicate the necessity to study different aspects of the biology of Chauliognathus spp. For instance, how does the male courtship behaviour differ from species to species? Does female behaviour change in response to feeding conditions? (RAUSHER \& FowLER 1979, for instance, found a positive association for the latter question). Could female sexual maturity determine the acceptance or rejection of a male? If so, the acceptance of a given male would be independent of his colour morph.

The reason for the maintenance of the polymorphism for elytra colour (if caused by assortative mating, natural selection or another agent) still remains to be explained satisfactorily. It is remarkable that several species of the genus
Chauliognathus show polymorphism for elytra and/or pronotum colour pattern. In the State of Rio Grande do Sul, for example, 5 out of 9 species already identified are polymorphic for elytra colour (Machado, unpublished). A survey of the literature showed that $C$. pennsylvanicus, C. basalis, and $C$. deceptus are also polymorphic for colour pattern (MCLAIN 1982, 1985; Bernstein \& Bernstein 1996, 1998). Could be there a common denominator for all these findings? Much remains to be done in order to provide an adequate answer to this question.

\section{REFERENCES}

Bernstein, R. \& S. Bernstein 1996. Color polymorphism and body size in males and females of Chauliognathus basalis (LeConte) (Coleoptera: Cantharidae). Coleopterists Bulletin 50: 297-300.

Bernstein, R. \& S. Bernstein 1998. Assortative mating by size in two species of Chauliognathus (Coleoptera:Cantharidae). Southwestern Naturalist 4: 62-69.

Diehl-Fleig, E. \& A. M. AraúJo 1991. O polimorfismo cromático em uma população natural de Chauliognathus fallax (Coleoptera: Cantharidae) do Rio Grande do Sul. Revista Brasileira de Biologia 51: 515-520.

ENDLER, J. A. 1978. A predator view of animals color patterns. Evolutionary Biology 11: 19-64.

EndLer, J. A. 1993a. Some general comments on the evolution and design of animal communication systems. Philosophical Transactions of tha Royal Society of London B 340: 215-225.

EndLeR, J. A. 1993b. The color of light in forests and its implications. Ecological Monographs 63: 1-27.

Hoffmann, A. A.; C. M. Sgró \& L. H. Lawler 1995. Ecological population genetics: the interface between genes and environment. Annual Review of Genetics 29: 349-370.

Machado, V. \& A. M. Araúdo 1995. The colour polymorphism in Chauliognathus flavipes (Coleoptera:Cantharidae) I. Geographic and temporal variation. Evolución Biológica 8/9: 127-139.

Machado, V. \& A. M. AraúJo 1998. Padrões de emergência em populações naturais de duas espécies de Chauliognathus (Coleoptera: Cantharidae). Revista Brasileira de Entomologia 41(2-4): 235238.

Machado, V. \& A. M. Araúso 1999. Color polymorphism in Chauliognathus flavipes Fab. 1781 (Coleoptera:Cantharidae) II. Patterns of emergence of morphs and mating systems. Revista Brasileira de Zoologia 16: 441-446.

Mason, L. G. 1972. Natural insect populations and assortative mating. American Midland Naturalist 88: 150-157.

McCauley, D. E. \& M. J. Wade 1978. Female choice and mating structure of a natural population of the soldier beetle, Chauliognathus pennsylvanicus. Evolution 32: 771-775.

McLain, D. K. 1982. Density dependent sexual selection and positive phenotipic assortative mating in natural population of the soldier beetle, Chauliognathus pennsylvanicus. Evolution 36: 1227-1235.

MCLAIN, D. K. 1985. Clinal variation in morphology and assortative mating in the soldier beetle, Chauliognathus pennsylvanicus (Coleoptera: Cantharidae). Biological Journal of the Linnean Society 25: 105-117.

Rausher, M. D. \& N. L. Fowler. 1979. Intersexual aggression and nectar defense in Chauliognathus distinguendus (Coleoptera:Cantharidae). Biotropica 11: 96-100.

Sokal, R. R. \& J. Rohlf 1995. Biometry. New York, W.H. Freeman and Company, 887 p. 